\title{
分析廖岛猛卡力斯与邦加里压河清明节传统习俗的区别 THE COMPARISON OF QINGMING FESTIVAL IN BENGKALIS CITY, RIAU, AND IN SUNGAILIAT, BANGKA
}

\author{
Agustinus S. (黎欢仁); Nita Anggastia; Yanti Hayani \\ Chinese Department, Faculty of Humanities, Binus University \\ Jl. Kemanggisan Ilir III No. 45, Kemanggisan/Palmerah, Jakarta 11480 \\ asufianto@binus.edu
}

\section{内容提要}

清明节在中国有着独特的地位, 是中华民族的重大纪念日, 对祖先的追悼与祭祖是传统社 会民众生活的重要内容, 所以祭祖仍为民族生活中的大事。清明节表现了一个孩子的孝心，对 父母或祖先的孝心报恩是一种具有德育美育教材的文化, 这传统文化从几千年代一直持续到现 在。笔者为了提高对廖岛猛卡力斯与邦加里压河清明节传统习俗的知识, 通过调查与采访做了 这项研究。在这项研究中, 笔者发现了廖岛猛卡力斯与邦加里压河的清明节传统习俗有很多区 别。围绕着这种情况笔者采访了那两个地方。

关键词：清明，节日，传统习俗

\begin{abstract}
Qingming Festival is a great festival and tradition for Chinese to commemorate their ancestors. This activity is considered necessary to do by Chinese nation. Qingming festival reflects xiaoxin (孝心) which means devotion toward the elderly or ancestor and is regarded as an educational culture. This tradition is well preserved until now. This study is objected to compare the Qingming festival held in Bengkalis City, Riau, and one held in Sungailiat, Bangka. By visiting directly those places and interviewing some Chinese people there, we will study and conclude some comparison on this subject.
\end{abstract}

Keywords: Qingming Festival, tradition, Chinese people, ancestor 


\section{前言}

人类生活在地球上，具有很多传统节日，几乎全国各地有他自己的节日特色。节日使生活 增添了光彩，也使生活有了希望，节日是紧张的放松，节日是必然的自由，节日是辛勤的快乐。 俗浐说 “阴司盼月半，小孩盼过年”。有了节日，人们就有了盼头。

“百里不同风，千里不同俗” 节日文化是多姿多彩的。不同的节日有不同的传说，不同的 习俗, 以及不同的祈祷方式。每一个传统节日承载着本民族的文化遗产，都记录着本民族的生 活习俗，民族的精神，心理和信仰。节日又是文化交流的最好平台。

清明节是中国重要的民间传统节日，是中国的祭祖节日。时间在农历 3 月，公历 4 月 5 日 前后。清明节与元宵节、立夏、端午节、中元节、中秋节、冬至和除夕并称 “八节”。各地清 明节习俗虽然不尽相同，但基本以扫墓祭祖、踏青郊游、寒食赐火为主题。

由于笔者分析的题目范围限定了这两个地方, 所以主要介绍了廖岛猛卡力斯与邦加里压河 的清明节传统习俗, 以及廖岛猛卡力斯与邦加里压河清明节传统习俗的区别。我们所知道不同 地方的节日有不同的习俗, 不同的祈祷方式, 以及不同的特色。

通过这个题目, 我们希望能够对那两个地方的清明节传统习俗更加了解, 还希望能够提高 我们对清明节的知识趣味，人与人之间的友谊，以及爱护文化。

\section{廖岛猛卡力斯清明节传统习俗}

廖岛猛卡力斯华人社会每年都有扫墓与为祖先祭拜的习俗。清明节, 人们纷纷到坟地进行 祖坟祭礼, 吒头与致敬，代表一个孩子的孝敬。此外，廖岛猛卡力斯华人社会认为以父母或祖 先的名义做善事，这样能够赞扬他们的恩惠也给他们带来欢喜。

在庆祝清明节，廖岛猛卡力斯华人社会有自己传统习俗的方法。自古以来，他们已有祭祖 与扫墓的习俗。一般廖岛猛卡力斯华人死后基本上用土葬, 做一个坟墓。每年清明, 他们就去 看望，整理一下坟前的草木，祭拜并供奉食物，还有烧金纸或纸币，纸所做的其他祭品如纸衣、 纸鞋等。这就是扫墓, 俗称“上坟”。祭扫的时间并不限定在清明当天，但在前十天，后十天的 范围内均可。民间有 “清明朝祖，前十后十”之说。所以，这些规定使人们更容易选择天内，尤 其是远方的亲人们。

按照廖岛猛卡力斯传统习俗, 清明节禁忌较多。首先是寒食禁火, 即在清明的前一天, 只 能吃准备好的凉菜。其次, 清明节当天不宜参加喜事如结婚这样的喜事, 如果要举行喜事的话, 也应避免在清明节当天。其三，扫墓不宜在黄昏或夜晚进行，扫墓严禁大声嬉笑，不许喧闹乱 跑, 否则视为对先人失敬。其四, 扫墓不宜穿红衣。最后按照传统习俗, 孕妇, 在例假中的女 性不能参加扫墓活动。 
在清明当天, 廖岛猛卡力斯华人社会比平常早点起床，他们正忙着准备祭扫的祭拜装备。 临去坟地之前, 为了获得祭扫祖坟的许可,他们在家里得先祭拜玉皇大帝。

每个祖坟之旁都有一个小的坟墓，这坟墓人称土神。据廖岛猛卡力斯华人社会的传统习俗， 祭拜祖坟之前, 他们得先祭拜土神。祭拜土神的目的是请求土地神让父母或祖先能来到人间, 打开大门让父母或祖先能过来跟我们会面。

祖坟所需要的祭品包括 :

1. 大香

2. 小香

3. 蜡烛

4. 金纸或纸币

5. 墓纸

6. 发糕

7. 仙头

8. 方形糕点

9. 水果

10. 红菠萝

11. 茶

12. 白酒

13. 白花

14. 糖果

土神所需要的祭品包括：

1. 小香

2. 蜡烛

3. 金纸或纸币

4. 墓纸

5. 仙头

6. 方形糕点

7. 水果

8. 白酒

9. 糖果

三支
三支 (每个人)
两支
不限制
不限制
一个
五个
五个
五个
两个
三杯
三杯
一盆
一包

五支 (每个人 )

两支

不限制

不限制

三个

三个

三个

一杯

一包

其他祭品如：纸衣、纸鞋、纸车、纸飞机和纸房等。祭礼过后他们把这些祭品火烧了。以 表示后辈给先人送来了日常用品。 
所有的祭品放在那两个坟墓之后（土神与祖坟），首先必须朝土神祭拜，祭拜土神并不需 要大香, 只用五支小香就可。按照传统, 必须是老一辈或家长先祭拜。朝土神用五支小香祭拜, 过后其他成员跟着祭拜。祭拜土神是请求土地神让他们的父母或祖先能来到人间，打开大门让 父母或祖先过来跟我们会面，以及让他们知道他们的子女或孙子女已经来探望了。

祭拜新土后，跟着就是祭拜祖坟。然而朝祖先祭拜，首先必须用三支大香，然后继续在墓 碑前用三支小香祭拜，其他成员跟着祭拜，只用三支小香就行。

祭礼过后，不久亲人们开始进行装墓活动，装墓就是装饰坟墓。通常他们使用墓纸贴在坟 墓的四周方面, 有的纸上可个以用小石头压着, 另放一沓在墓碑上。坟上的墓纸作为坟地的顶 棚，他们相信有了这个顶棚能给先人保暖，免先人躺在地下受凉。

最后是火烧纸钱仪式。他们相信火烧了的纸钱能直接寄给先人，有了纸钱，希望祖先在阴 间和平生活，也表现尊敬上代祖宗。除了烧纸钱之外，还把所带的用纸所做的其他祭品，如： 纸衣、纸鞋、纸车、纸飞机、纸房等火烧了。这都是根据梦中所收到的先人要求而定, 如果没 有收到要求的话, 就不必进行火烧其他祭品仪式。火烧纸钱后, 亲人们开始朝祖坟和土神行礼, 双手合起来位于胸前，叨头行礼，再返回家中。

\section{邦加里压河清明节传统习俗}

邦加里压河华人社会到现在仍庆祝清明节，通称清明扫墓。在华族生活中，清明节主要是 纪念祖先的日子。邦加里压河的华人社会, 至到现在有庆祝清明节的风俗习惯是清扫和祭拜自 己祖先的坟墓。邦加里压河华人社会都相信如果我们做善事，我们能赞扬祖先的恩惠，赞扬祖 先的教育和相信冥冥中能帮祖先在阴界有幸福的生活。

在庆祝清明节，邦加里压河华人社会有祭祖和清扫坟墓的习俗。邦加里压河华人把已仙逝 的亲人殓于棺木，然后以佛礼好好的安葬，做了一个坟墓。每年清明节，亲戚纷纷探望祖先的 坟墓, 清扫、祭拜、奉献各种食物还有烧金纸、纸衣或纸所做的其他祭品。这就是祭祖。清明 扫墓没肯定时间多长，主要到了清明节，全家一大早就起床，冲洗干净，换了清洁衣服，一家 人欢欢喜喜去看亲人。按照邦加里压河传统习俗, 庆祝清明节只有一个禁忌, 就是在例假中的 女性不能祭拜土神, 但可以祭拜祖坟。

每个祖坟之旁都有一个小坟墓。这小坟墓人称土神。根据邦加里压河华人社会的传统习俗， 祭拜祖坟前, 他们得先祭拜土神。祭拜土神是请求土神把关闭了的阴界大门打开了, 使得父母 或祖先能过来跟我们会面, 看看他们亲爱的子孙。祭拜土神和祖坟前, 他们必须准备所需要的 祭品，那些祭品都放在那两个坟墓上。 
祖坟所需要的祭品包括 :

1. 大香

2. 小香

3. 蜡烛

4. 金纸

5. 茶

6. 白酒

7. 米饭

8. 熟鸡

9. 遮目鱼

10. 熟猪

11. 豆腐与丸子汤

12. 鸡蛋

13. 汤圆

14. 梨子

15. 苹果

16. 桔子

17. 菠萝

18. 糕点

19. 芝麻球糕

20. 新鲜草

土神所需要的祭品包括：

1. 大香

2. 小香

3. 蜡烛

4. 金纸

5. 茶

6. 白酒

7. 米饭

8. 熟鸡

9. 遮目鱼

10. 熟猪

11. 梨子

12. 苹果
三支

九支 (每个人)

两支

不限制

三杯

五杯

一碗

一个

一个

七克

一碗

一盘

一碗

三个

三个

三个

两个

三个

三个

一盆

三支

九支 (每个人)

两支

不限制

一杯

一杯

一碗

一个

一个

七克

一个

一个 
13. 桔子

14. 糕点

一个

15. 芝麻球糕

其他祭品如：纸衣、纸鞋、纸车、纸飞机和纸房。他们把献给祖先的这些祭品火烧了, 相 信在阴界中能收到。

所有祭品放在那两个坟墓后, 首先必须朝土神祭拜。按照传统习俗, 家长或老一辈先拜土 神, 必须用三支大香, 接下去是九支小香。过后才轮到其他家族成员, 用九支小香就可。烧过 了的香都须插入在坟墓的祭坛。祭柏土神是请求土地神把阴界大门打开了, 使得父母或祖先能 过来跟亲爱子孙会面，心灵之会面。

祭拜土神后, 跟着就是祭拜祖坟。然而现只须三支大香, 然后继续用九支小香。其他成员 跟着祭拜, 只用九支小香就可以。烧过了的香都须插入在坟墓的祭坛。烧了香后, 我们必须再 用手祭拜，双手合起来位于胸前，恭恭敬敬的行了三鞠躬。

祭拜过后，子孙们开始装饰坟地和拔草种花。把金纸折成一条小小花，然后全部都插入在 祖坟上，作为坟地的顶棚，他们相信有了这个顶棚能给已仙逝了的祖先或父母亲保暖，免他们 躺在地下受冷了。除了把金纸折成小花以外，他们也常把金纸折成两条长带子，放在坟地的左 右面上, 这两条长带子又给坟地另一优美的风光。然后插些小蜡烛围绕坟地的边缘, 作为坟地 的篦笆。

最后的仪式是火烧金纸或纸币，按照传统习俗，金纸或纸币火烧了就能给先人带来安全。 有了金纸或纸币, 希望能帮助祖先或父母在阴界避免贫穷的生活。除了烧金纸或纸币以外, 也 把所带了的用纸所做的其他祭品，如：纸衣、纸鞋、纸车、纸飞机和纸房火烧了。火烧金纸等 后, 还必须等全香都烧剩不多了, 就是扫墓时间快要结束了, 亲友开始朝祖坟和土神行礼, 双 手合起来位于胸前，恭恭敬敬的行了三鞠躬，一边在心里祷告求祖先或父母在九泉之下保留我 们生活快乐，身体健康。

\section{廖岛猛卡力斯与邦加里压河清明节传统习俗的 对比研究}

通过这项研究，笔者发现了猛卡力斯与里压河的清明节习俗有些区别，即：祭品方面的区 别，传统习俗方面的区别，祭礼方面的区别，装饰坟墓方面的区别，以及禁忌方面的区别。

在这两个地方, 最明显的区别是在扫墓的时间。猛卡力斯的扫墓时间并不限定在清明节当 天，但前十天，后十天的范围内均可，但里压河只在清明节当天举行而已。 
第一节 祭品方面的区别

\section{表一、廖岛猛卡力斯与邦加里压河的土神祭品的对比}

\begin{tabular}{|c|c|c|c|}
\hline \multicolumn{2}{|c|}{ 廖岛猛卡力斯 } & \multicolumn{2}{|c|}{ 邦加里压河 } \\
\hline 祭品 & 总数 & 祭品 & 总数 \\
\hline \multirow[t]{2}{*}{ 小香 } & 五支 & 大香 & 三支 \\
\hline & & 小香 & 九支 \\
\hline 蜡烛 & 两支 & 蜡烛 & 两支 \\
\hline 金纸或纸币 & 不限制 & 金纸 & 不限制 \\
\hline 墓纸 & 不限制 & 无 & 无 \\
\hline 白酒 & 一杯 & 白酒 & 一杯 \\
\hline 无 & 无 & 茶 & 一杯 \\
\hline 无 & 无 & 米饭 & 一碗 \\
\hline 无 & 无 & 熟鸡 & 一个 \\
\hline 无 & 无 & 遮目鱼 & 一个 \\
\hline 无 & 无 & 熟猪 & 七克 \\
\hline 仙头 & 三个 & 糕点 & 一个 \\
\hline 方形糕点 & 三个 & 芝麻球糕 & 一个 \\
\hline \multirow[t]{3}{*}{ 水果 } & 三个 & 梨子 & 一个 \\
\hline & & 苹果 & 一个 \\
\hline & & 桔子 & 一个 \\
\hline 糖果 & 一包 & 无 & 无 \\
\hline
\end{tabular}

廖岛猛卡力斯的土神祭品之意：

一、五支小香代表五行 ( 金、木、水、火、土 )。烟能传 的很远, 代表长久, 永恒; 香的香 味敬给土神。

二、两支蜡烛代表亮光与平衡。

三、金纸或纸币是已故者用的纸钱。又是祭祖所烧的纸钱。

四、墓纸是五色纸剪成长方形，用来装饰土神坟地。

五、一杯白酒是敬给土地公公掲的。表达慰劳和感恩之意。

六、三个仙头是敬给土地公公吃的。

七、三个方形糕点是扫墓的主要糕饼。每年清明节，廖岛猛卡力斯华人都做这种糕饼。 
八、三个水果, 因为土地公公只有一位, 所以三个就够了。而且他们相信奇数有成功的含义。

九、一包糖果以示亲人们在一年里就会过一个甜蜜的日子。

邦加里压河的土神祭品之意：

一、三支大香的意思是代表三路（陆、海、空），烟能传 的很远代表长久，永恒; 香的香味 敬给土神。

二、九支小香, “九”字来由是“九九长”, 代表长命百 寿, 前途长远, 希望凡是吉祥之事都能久。

三、两支蜡烛代表亮光与平衡。

四、金纸代表银行支票。

五、一杯白酒是敬给土神喝的。

六、一杯茶是敬给土神喝的。

七、一碗米饭是敬给土神吃的。

八、熟鸡，遮目鱼，和熟猪是用来敬给土神的。

九、一个糕点和芝麻球糕是敬给土神吃的，因为在邦加里 压河很容易买到的，所以用这两糕 饼。

十、一个梨子, 苹果和桔子, 这些水果也是敬给土神吃的; 水果不多, 因为土神只有一位。

表二、廖岛猛卡力斯与邦加里压河的祖坟祭品的对比

\begin{tabular}{clll}
\hline \multicolumn{2}{c}{ 廖岛猛卡力斯 } & \multicolumn{2}{c}{ 邦加里压河 } \\
\hline 祭品 & 总数 & 祭品 & 总数 \\
\hline 大香 & 三支 & 大香 & 三支 \\
小香 & 三支 & 小香 & 九支 \\
蜡烛 & 两支 & 蜡烛 & 两支
\end{tabular}

\begin{tabular}{cccc} 
金纸或纸 & 不限制 & 金纸 & 不限制 \\
墓纸 & 不限制 & 无 & 无 \\
白酒 & 三杯 & 白酒 & 五杯 \\
茶 & 三杯 & 茶 & 三杯 \\
无 & 无 & 米饭 & 一碗 \\
无 & 无 & 熟鸡 & 一个 \\
无 & 无 & 遮目鱼 & 一个 \\
无 & 无 & 熟猪 & 七克 \\
无 & 无 & 豆腐与丸子汤 & 一碗 \\
无 & 无 & 鸡蛋 & 一盘 \\
\hline
\end{tabular}




\begin{tabular}{cccc}
\hline 无 & 无 & 汤圆 & 一碗 \\
发糕 & 一个 & 糕点 & 三个 \\
仙头 & 五个 & 芝麻球糕 & 三个 \\
方形糕点 & 五个 & & \\
水果 & 五个 & 梨子 & 三个 \\
红菠萝 & 两个 & 苹果 & 三个 \\
& & 桔子 & 三个 \\
& & 菠萝 & 两个 \\
糖果 & 一包 & 无 & 无 \\
白花 & 一盆 & 新鲜草 & 一盆 \\
\hline
\end{tabular}

廖岛猛卡力斯的祖先祭品之意：

一、三支大香代表三代 (曾祖父、祖父、父亲)。又表示

尊敬上代祖宗。

二、三支小香, 表示对已故者的感恩图报, 烟能传的很远

代表长久, 永恒; 香的香味敬给先人。

三、两支蜡烛代表亮光与平衡。

四、金纸或纸币是已故者用的纸钱。本意是希望祖先在阴 间和平生活, 不受穷, 以及表达对已故亲人的感恩。

五、墓纸是五色纸剪成长方形, 用来装饰祖坟。

六、三杯白酒是代表三代 (曾祖父、祖父、父亲)。又表 示亲密无间。

七、三杯茶是代表三代 (曾祖父、祖父、父亲)。扫墓敬茶是廖岛猛卡力斯华人社会的风俗 习惯。

八、一个发糕以示家家户户年年进步发大财。

九、五个仙头是先人喜欢吃的糕饼。五个代表五行 ( 金、 木、水、火、土)。

十、五个方形糕点是扫墓的主要糕饼。五个代表五行 ( 金、 木、水、火、土)。

十一、两个红菠萝以示招来喜气和吉祥。两个代表万事平衡 , 悲欢平衡。

十二、一包糖果以示亲人们在一年里会过一个甜蜜的日子。

十三、一盆白花代表先人花园的草木。 
邦加里压河的祖先祭品之意：

一、三支大香的意思是代表三代（曾祖父、祖父、父亲），又可解释为三路（陆、海、 空），意思是广泛开路。

二、九支小香，“九”字来由是“九九长”, 代表长命百寿, 前途长远, 希望凡是吉祥之事都能 长久。

三、两支蜡烛代表阴阳平衡，万事平衡。古人都很聪明，蜡烛需要两支因为如果只有单支， 放左放右都不方便，放在正中呢，有遮住了大香与神位。别忘了，这些传统是古代传下 来的，古代的人穿的长袍都是又长又阔的长袖袍，一不小心被火烧了。

四、金纸代表银行支票。

五、五杯白酒代表五行 ( 金、木、水、火、土 )。

六、三杯茶代表三代（曾祖父、祖父、父亲），又象征三敬茶，尊敬上代祖宗。

七、一碗米饭是敬给祖宗吃的。

八、熟鸡, 遮目鱼, 和熟猪, 又称三生, 意思是三种有生命的动物。这三生是人们通常喜爱 吃的也是最易买到的。

九、豆腐与丸子汤，鸡蛋，汤圆，是三种已故者最喜爱的食物。

十、三个蛋糕与芝麻球糕是敬给祖宗吃的, 因为在邦加里压河很容易买到的, 所以用这两种 糕饼。每种糕饼有三个是代表上三代（曾祖父、祖父、父亲）。

十一、三个梨子，苹果和桔子，这些水果除了颜色好看以外，也是很普通的水果，很容易买到。 每种水果有三个代表三代 (曾祖父、祖父、父亲)。但是如果放于一个小盘子上，那么 三个水果排起来就好看。

十二、两个黄梨 (菠夢) , 梨的发音与“利”相同是代表有利, 利益; 有利于他们下一代。菠萝 有两个代表生活平衡, 生计平衡。

十三、一盆新鲜草代表蔬菜也代表他们花园的草木。

\section{第二节 传统习俗方面的区别}

廖岛猛卡力斯与邦加里压河清明节习俗的区别：

一、在廖岛猛卡力斯, 祭扫的时间并不限定在清明当天, 但在前十天, 后十天的范围内均可 但在邦加里压河，清明扫墓没肯定时间多长，主要是在清明当天。

二、按照邦加里压河华人社会传统习俗，祭扫时，必须火烧用纸所做的其他祭品。但廖岛猛 卡力斯华人社会相信, 火烧其他祭品都是根据梦中所收到的先人要求而定, 如果没有受 到要求的话, 就不必进行火烧其他祭品仪式。

三、在庆祝清明节，廖岛猛卡力斯华人社会除了祭扫之外，还喜欢进行些户外活动，如踏 青，放风筝。放风筝是廖岛猛卡力斯华人社会清明节时所喜爱的活动。这个活动到今还 
有，他们相信清明节放风筝可以祛病祈福。但是在邦加里压河华人社会，他们没有进行 任何户外活动。

\section{第三节 祭礼方面的区别}

廖岛猛卡力斯的祭礼：

一、临去坟地之前, 为了获得祭扫祖坟的许可,他们在家里得先祭拜玉皇大帝。

二、祭拜土神是祭扫过程中的最初仪式，祭拜祖坟之前，他们得先祭拜新土。按照传统， 必须是老一辈或家长先祭拜。朝新土用五支小香祭拜, 过后其他成员跟着祭拜。

三、朝祖坟祭拜，首先必须用三支大香，然后继续在墓碑前用三支小香祭拜，其他成员跟 着祭拜，只用三支小香就行。

四、祭礼过后，不久亲人们开始进行装墓活动，装墓就是装饰坟墓。

五、最后是火烧纸钱仪式。除了烧纸钱之外，还把献给先人的其他祭品例如：纸衣、纸鞋、 纸车、纸飞机、纸房等火烧了 ( 不须)。

邦加里压河的祭礼：

一、按照传统习俗, 祭拜祖坟前, 他们得先祭拜土神。首先家长必须用三支大香祭拜, 接下 去用九支小香。过后才轮到其他家族成员，用九支小香就可以。

二、祭拜祖坟, 首先用三支大香, 然后继续用九支小香。其他成员跟着祭拜, 只用九支小香 就可以。

三、祭拜过后, 子孙们开始装饰坟地和拔草种花。

四、最后的仪式是火烧金纸或纸币。除了烧金纸或纸币以外，也把所带了的用纸所做的其他 祭品，例如：纸衣、纸鞋、纸车、纸飞机和纸房火烧了（必须）。

\section{第四节 装饰坟墓方面的区别}

廖岛猛卡力斯的装饰坟墓活动：

一、平常使用五色墓纸装饰坟墓。

二、通常他们把墓纸贴在坟墓的四周献置, 有的纸上可以用小石头压着, 另放一沓在墓碑 上。这沓墓纸又给祖坟另一优美的风光。

三、坟上的墓纸作为坟地的顶棚，他们相信有了这个顶棚能给先人保暖，免先人躺在地下受 凉。

邦加里压河的装饰坟墓活动：

一、平常使用金纸装饰坟墓。 
二、通常他们把金纸折成一条小小花, 然后全部都插入在祖坟上, 作为坟地的顶棚, 我们相 信有了这个顶棚能给已故者保暖。

三、金纸也折成两条长带子, 放在坟地的左右面上, 这两条长带子又给坟地另一优美的风 光。

四、插些小蜡烛围绕坟地的边缘, 作为坟地的篦笆。

第五节 禁忌方面的区别

廖岛猛卡力斯的清明节禁忌：

一、寒食禁火, 即在清明的前一天, 只能吃准备好的凉菜。这是为了纪念介之推的牺牲, 因 为介之推的传说与寒食节相干密切。

二、清明节当天不宜参加喜事; 结婚这样的喜事, 也应避免在清明节当天举行。因为清明节 是祭祖节日，而婚事是一种喜事，所以祭祖与喜事相对，这恐怕一生会不吉利。

三、扫墓不宜在黄昏或夜晚进行，扫墓严禁大声嬉笑，不许喧闹乱跑,否则视为对先人失敬。

四、扫墓不宜穿红衣。原因是因为红色是代表喜气, 所以扫

墓不可以穿红衣。

五、孕妇，在例假中的女性不能参加扫墓活动，否则会对先人与土神失敬。

按照邦加里压河传统习俗, 庆祝清明节只有一个禁忌即在例假中的女性不能祭拜土神, 但 可以祭拜祖坟。由于土地公公是一位神仙, 地位比先人高的多, 所以我们得尊敬他。

\section{结论}

廖岛猛卡力斯与邦加里压河华人社会到现在还进行和庆祝清明节传统习俗。他们认为清明 节有独特的地位, 是中华民族的重大纪念日, 对祖先的追悼与祭祖是传统社会民众生活的重要 内容。

在庆祝清明节, 廖岛猛卡力斯与邦加里压河华人社会有自己传统习俗的方法。这两个地方 的清明节习俗虽然不尽相同, 但基本以扫墓祭祖为主题。每年清明节, 他们就去探望祖先的坟 墓、清扫、祭拜、供奉各种食物还有烧金纸、纸币、纸衣或纸所做的其他祭品。这就是祭祖。 通过这项研究, 笔者发现了廖岛猛卡力斯与邦加里压河的清明节传统习俗有很区别。所以笔者 从几个方面分析这些区别, 即祭品方面的区别, 传统习俗方面的区别, 祭礼方面的区别, 装饰 坟墓方面的区别，以及禁忌方面的区别。

祭品方面的区别可以从食物来看, 例: 在猛卡力斯一般素食, 但在里压河一般用肉类。传 统习俗方面的区别可以从祭扫时间来看, 例: 在猛卡力斯祭扫时间并不限定在清明节当天, 但 在里压河只在清明节当天而已。祭礼方面的区别可以从小香数量来看, 例: 在猛卡力斯, 祭拜 祖坟用三支小香, 在里压河却用九支小香。装饰坟墓方面的区别可以从不同的纸类看, 猛卡力 斯一般用彩色墓纸，但里压河用金纸。还有禁忌方面的区别，猛卡力斯的清明节禁忌比里压河 较多。 


\section{参考文献}

何红烈. (2009). 中国节日. 四川: 四川出版集团.天地出版社.

赵小玉. (2001). 信仰文化. 开封: 河南大学出版社.

韩鉴堂. (2002). 中国文化. 北京: 北京语言大学出版社.

刘小玲. (2004). 青年必读知识图典. 中国文化素质读本. 北京: 人民日报出版社.

李慕南, 张林, 李丽丽. (2005). 中国传统节日. 开封: 河南大学 出版社.

张君. (2004). 中华神秘文化习俗. 广西: 广西人民出版社.

许雅萍. (2005). 中国节日故事. 台北: 世一文化.

Danandjaja, James. (2007). FolklorTionghua. Jakarta: Gramedia.

Fu Chun Jiang. (2001). Origins of Chinese Festivals. Jakarta: Elex Media Komputindo.

Mahsun, M.S. (2005). Metode Penelitian Bahasa. Jakarta: Rajagrafindo Persada.

Rusnaini. (2006). KehidupanSosialBudayaEtnisCina di Pulau Bangka: Studi Kasus di Kecamatan Sungailiat, Kabupaten Bangka. Humaniora, 12 (1), 99 - 114.

Suryadinata, Leo. (2002). Kebudayaan Minoritas Tionghoa di Indonesia. Jakarta: Gramedia.

Wangseng, Ann. (2001). Kepercayaan Orang China. Shah Alam: Fajar Bakti.

Wibisana, Wahyu. (2009). Hari-hari Raya Tionghoa. Jakarta: Suara Harapan Bangsa.

Yuanzhi, Khong. (2004). Peradaban Tionghoa Selanjang Pandang. Jakarta: Bhuana Ilmu Populer.

Yusuf, Tedy. (2001). Sekilas Budaya Tionghua di Indonesia. Jakarta: Bhuana Ilmu Populer. 